This paper is a post-print of a paper submitted to and accepted for publication in The 15th IET International Conference-AC and DC Power Transmission (ACDC 2019) and is subject to Institution of Engineering and Technology Copyright. The copy of record is available at IET Digital Library.

\title{
Interoperability of Different Voltage Source Converter Topologies in HVDC Grids
}

\author{
Deyang Guo ${ }^{1 *}$, M.H. Rahman', G.P. Adam ${ }^{1}$, Lie Xü ${ }^{1}$, Abdullah Emhemed ${ }^{1}$, Graeme Burt ${ }^{1}$ and Yash \\ Audichya ${ }^{2}$ \\ ${ }^{1}$ University of Strathclyde, Glasgow, UK, ${ }^{2}$ The National HVDC Centre, Glasgow, UK \\ deyang.guo@strath.ac.uk
}

Keywords: Interoperability; Voltage source converter; HVDC transmission systems; modular and hybrid multilevel converters; multi-terminal DC grids; offline and real-time simulations.

\begin{abstract}
This paper presents a detailed study of DC grid operation using a range of user-defined offline and real-time HVDC converter models which were rigorously validated against offline and real-time benchmarks. Provided that these models are destined for use in real-time hardware in the loop simulation and a wide range of offline system studies, this paper assesses their suitability for studying complex DC grids that consist of multiple voltage source converters which differ in their control range and fault ride-through capabilities. Detailed quantitative studies show that the offline and real-time DC grid models produce well matched results and provide efficient approaches to investigate DC grid operation during normal condition and $\mathrm{AC}$ and DC faults.
\end{abstract}

\section{Introduction}

In the last decade, a number of multilevel voltage source converters have been proposed for HVDC applications. Halfbridge (HB) and full-bridge (FB) modular multilevel converters (MMC) have emerged as the preferred topologies for commercial application to multi-terminal HVDC grids. In the meantime, several hybrid converters have been proposed as alternatives that offer important trade-offs between footprint, semiconductor loss, resiliency to AC and DC network faults and control range. Some of these hybrid converters are becoming increasingly attractive as they offer bespoke features, ranging from that of the HB-MMC to the FB-MMC.

Although the construction of large-scale DC grids using different converter topologies is important from both practical and market point of view, particularly for prevention of monopoly in supply chains, ensuring safe and reliable operation of DC grids with such diversity, present significant technical challenges; especially, during fault conditions.

Meaningful assessments of the interoperability of such complex DC grids, with equipment supplied by multiple vendors, require converter models with steady-state and transient behaviours that accurately resemble the typical behaviour of physical systems. All converter terminals (regardless of their topologies) must be designed to ensure that their steady-state and transient responses are confined within narrow band and with defined settling and rise times, maximum overshoots, permissible oscillating frequency, and damping in order to avoid undesirable interactions between converters.

With regard to modelling, concerted efforts from academia and industry in the last decade have resulted in development of universal modelling frameworks for MMC and hybrid converters, namely, Thevenin equivalent model which was initially developed in 1969 by Dommel in [1] and then extended to MMC in [2, 3], generalized switching function model [4-6], and averaged model [7, 8]. Detailed studies presented in [3, 6, 9-13] confirm that all the aforementioned models are capable of reproducing the typical behaviours of modular and hybrid converters during normal operation, and $\mathrm{AC}$ and DC faults.

Equally, the control of MMC and hybrid converters is extensively investigated in the last decade [14-22]. There are two common methods for controlling MMC and hybrid converters. The first method only manipulates the phase and magnitude of the AC voltage component for each phase-leg relative to that of $\mathrm{AC}$ grid as that in the two-level converter, with the DC components of the phase-legs fixed. The second method manipulates both $\mathrm{AC}$ and DC components of each phase leg to control active and reactive powers, and to decouple capacitor voltage regulation and dynamics from that of the DC link voltage.

The second control method allows the HB-MMC to control its DC link independent of the cell capacitor voltages and vary its DC link voltage and retain control as long as the DC voltage remains above the peak of the line-to-line voltage being imposed by the $\mathrm{AC}$ grid at its $\mathrm{AC}$ terminals. It permits $\mathrm{FB}-$ MMC to offer maximum control range in addition to DC fault blocking, i.e., controlled operation over wide range of positive and negative DC link voltages. Similarly, besides the DC fault blocking, hybrid MMC with 50\% FB cells and 50\% HB offers controlled operation between zero to rated positive DC link voltage.

Because of numerous mismatches between the attributes and capabilities of the voltage source converters briefly highlighted earlier, this paper examines the suitability of the offline and real-time converters' models being developed in this study for detailed assessment of interoperability of different converters in a meshed DC grid. Interoperability of a few selected 
This paper is a post-print of a paper submitted to and accepted for publication in The 15th IET International Conference-AC and DC Power Transmission (ACDC 2019) and is subject to Institution of Engineering and Technology Copyright. The copy of record is available at IET Digital Library.

representative converter topologies, namely, the $\mathrm{HB}$ and $\mathrm{FB}$ MMCs and hybrid MMC consisting of $50 \%$ FB cells and $50 \%$ $\mathrm{HB}$ will be assessed quantitatively using offline PSCAD and real-time RSCAD simulations. This study models all converter terminals using validated averaged models against their switching function equivalents in PSCAD and RSCAD with all main and auxiliary controllers incorporated [11].

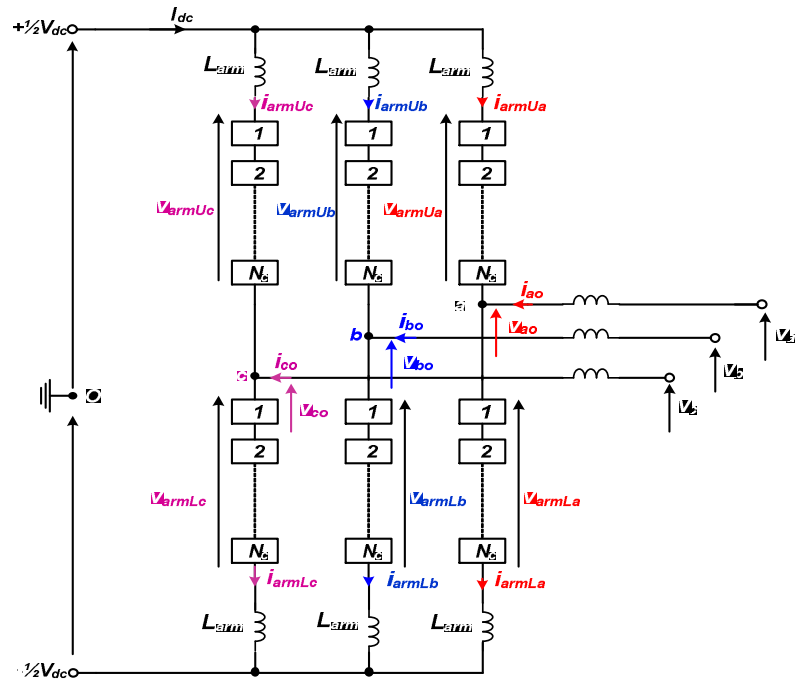

Fig. 1: Basic circuit of three-phase modular multilevel converter

\section{Converters modelling and control}

\subsection{Modelling}

Fig. 1 shows a generic power circuit of a three-phase MMC converter. It consists of six arms, with each arm comprising of an inductor and a chain link of HB or FB cells, or combination of the HB and FB cells. Fig. 2(a) shows generic phase legs of the HB and FB MMCs and of the hybrid MMC. The upper and lower arm voltages $\left(V_{\text {arm } U}\right.$ and $\left.V_{\text {armL }}\right)$ of the converters in Fig. 1 can be approximated as:

$$
\begin{aligned}
& V_{\text {armU }} \approx \frac{1}{2} V_{\text {camm }}[\alpha-m \sin (\omega t+\delta)] \approx V_{\text {cam }} m_{U} \\
& V_{\text {armL }} \approx \frac{1}{2} V_{\text {carmL }}[\alpha+m \sin (\omega t+\delta)] \approx V_{\text {carmL }} m_{L}
\end{aligned}
$$

where $V_{\text {carmu }}$ and $V_{\text {carmL }}$ are the sums of the upper and lower arm capacitor voltages, and must be regulated such that
$V_{\text {carmu }}=V_{\text {carmL }}=V_{\text {carm }}^{*} \geq V_{d c} \quad\left(V_{\text {carm }}^{*}\right.$ is the rated arm capacitor voltage). $\alpha$ is the DC modulation index defined as $\alpha=V_{d c} / V_{\text {carm }}^{*}$ , $m_{U}$ and $m_{L}$ are the upper and lower arms modulation functions, respectively. For HB and FB MMCs, DC modulation indexes ' $\alpha$ ' vary narrowly around 1 and $-1 \leq \alpha \leq 1$, respectively. Fig. 2 (b) and (c) depict per arm averaged models of the half-bridge and full-bridge MMCs [7, 11, 23, 24], where the equivalent upper and lower capacitor currents $i_{c a p U}$ and $i_{c a p L}$ are:

$$
\begin{gathered}
i_{a p u} \approx \frac{1}{2} i_{a m U}[\alpha-m \sin (\omega t+\delta)] \approx i_{a r m U} m_{U} \\
i_{c a p L} \approx \frac{1}{2} i_{a r m L}[\alpha+m \sin (\omega t+\delta)] \approx i_{a r m L} m_{L}
\end{gathered}
$$

Realization of blocking state in HB-MMC model in Fig. 2 (b) is achieved by adding the auxiliary devices $S_{x}$ and $D_{m}$ [11]. In FB-MMC model in Fig. 2 (c), blocking state is realized by gating off the insulated gate bipolar transistors (IGBTs) $S_{1}, S_{2}$, $S_{3}$ and $S_{4}$, and setting the upper and lower arm modulation functions $m_{U}=m_{L}=1$. The upper and lower arm voltages during de-block state are realized as:

$$
\begin{aligned}
& V_{a m U} \approx V_{\text {camu }}\left|m_{U}\right| \\
& V_{a m L} \approx V_{\text {cammL }}\left|m_{L}\right|
\end{aligned}
$$

In addition, when $\operatorname{sign}\left(m_{U}\right) \geq 0$ the switches $S_{1}$ and $S_{4}$ are turned on and $S_{2}$ and $S_{3}$ are turned off, and the opposite is true for $\operatorname{sign}\left(m_{U}\right)<0$. The former scenario arises when FB-MMC arm synthesizes positive voltages, and latter scenario when the FBMMC arm synthesizes negative voltages. The hybrid MMC facilitates normal and reduced DC link voltage operation and active control of DC fault current during pole-to-pole DC fault (zero DC voltage) by inserting the same number of cell capacitors with positive and negative polarities as that of the FB-MMC. Thus, provided that the HB and FB cells of the hybrid MMC have same capacitances, insertion of the FB cell capacitors with positive polarities will exhibit the same behaviours at cell and arm levels as that of the HB cells. This fact justifies the use of per arm averaged model depicted in Fig. 2(c) to represent the hybrid MMC (or mixed-cell MMC), provided the DC modulation control range is restricted as described above, and upper and lower arm modulation functions $m_{U}$ and $m_{L}$ are set to $1 / 2$ during converter blocking.

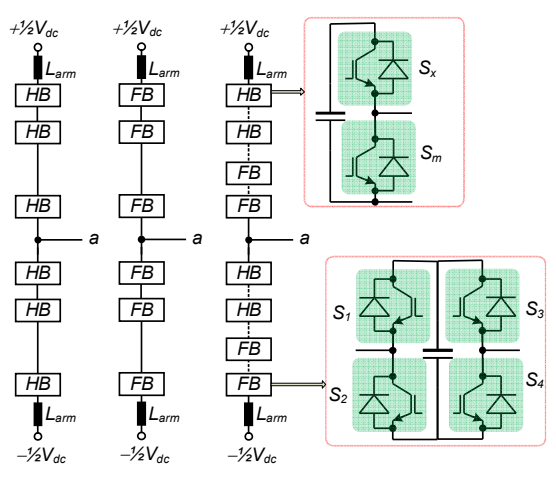

(a)

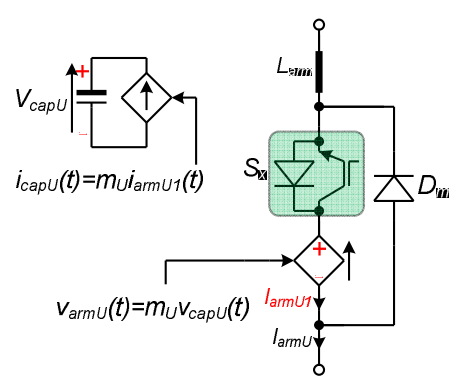

(b)

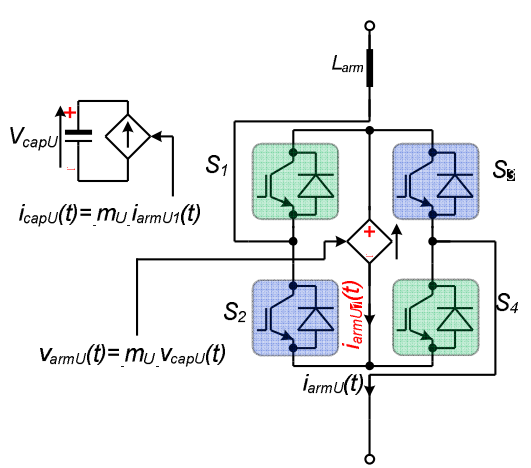

(c)

Fig. 2: Generic depictions of: (a) Phase-legs of half and full-bridge Modular and hybrid converters, (b) Enhanced per arm averaged model of the half-bridge MMC, (c) Enhanced per arm averaged model of full-bridge and hybrid MMC. 
This paper is a post-print of a paper submitted to and accepted for publication in The 15th IET International Conference-AC and DC Power Transmission (ACDC 2019) and is subject to Institution of Engineering and Technology Copyright. The copy of record is available at IET Digital Library.

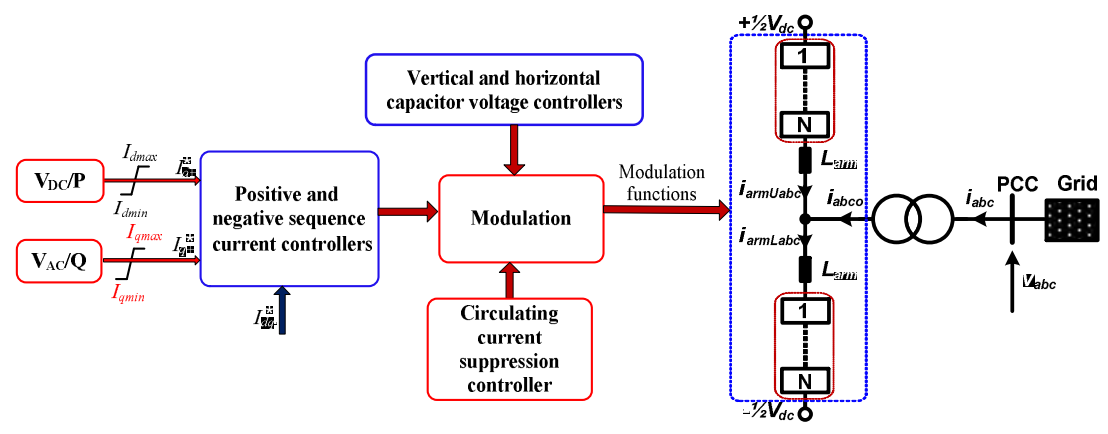

Fig. 3: High-level block diagram of the main and auxiliary MMC controllers

\subsection{Control system}

Fig. 3 summarises the main and auxiliary controllers employed in this paper with HB, FB MMCs and hybrid MMC. The outer controllers on $\mathrm{d}$-axis regulate active power or DC voltage and set the positive sequence d-axis current order. Likewise, the outer controllers on q-axis regulate reactive power or $\mathrm{AC}$ voltage and set the positive sequence q-axis current order. The inner current controllers regulate both positive and negative sequence currents and limit current contribution to $\mathrm{AC}$ fault and generate the $\mathrm{AC}$ components of the modulation functions. The negative sequence $\mathrm{d}$ - and q-axis current orders are set to zero to ensure balanced three-phase output currents during operation in unbalanced AC grids and asymmetric AC faults, but their orders can be set to other values if negative sequence current is required. Circulating current controller is implemented in each phase leg to suppress the $2^{\text {nd }}$ order harmonic currents in the arms of the converters to reduce semiconductor power losses and cell capacitor voltage ripples. Horizontal and vertical cell capacitor voltage controllers are implemented to ensure equal voltage distribution across the three phase-legs of the converters and across the upper and lower arms of each phase leg. With averaged converter models adopted in this paper, each arm in Fig. 3 will be replaced by the averaged arms in Fig. 2 (b) or (c), depending on the converter topology to be simulated.

\section{Test system}

Fig. 4 shows an example test system being used to assess the interoperability of $\mathrm{HB}$ and FB MMCs and hybrid MMC in a generic DC grid. Converters $\mathrm{T}_{1}, \mathrm{~T}_{2}$ and $\mathrm{T}_{3}$ are hybrid $\mathrm{MMC}$, FB-MMC, and HB-MMC respectively. All converters are represented in PSCAD-EMTDC and RTDS-RSCAD by their averaged models described in Section 2.1 and shown in Fig. 2 (b) and (c). The control system depicted in Fig. 3 is incorporated into each converter station. Simulation parameters of the test systems are shown in Fig. 4.

The DC grid shown in Fig. 4 is implemented in RTDS using the concept of multi-rate, with two distinct sampling times. The power circuits of the three converters and DC cables are placed in 3 processors on GPC cards that operate at $2.5 \mu$ s time step. The three AC grids, control systems and part of the averaged model that calculates the capacitor voltage dynamics, operate at $50 \mu$ s time step. Three AC sources that represent the AC grids and dynamics of the averaged model are placed in 2 processors on GPC card. The AC sides of the three converter models that operate at $2.5 \mu \mathrm{s}$ (small) time-steps are interfaced to the $\mathrm{AC}$ grids that operates at $50 \mu \mathrm{s}$ (large) time-step via three interfacing transformers. The DC side of the converter model and associated DC cable operate at small time-step but in different processors and are linked together through very short T-lines to form a DC grid.

It is worth emphasizing that the uses of T-lines for connecting converter models and DC cables that operate on different processors and the interfacing transformers for connecting system components that operate with different sample times have negligible impact on the accuracy of the real-time simulation, which will be demonstrated later.

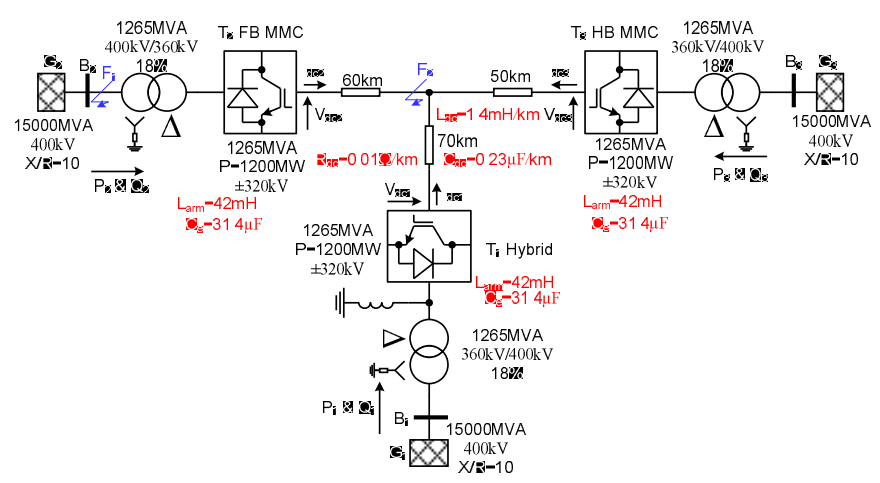

Fig. 4: Illustrative DC grid with multiple converter topologies

\section{Simulations}

This section examines the use of the developed offline and realtime converter models described in Sections 2 and 2.2 to assess the performance of DC grid that consists of multiple converter topologies, considering normal operation and fault conditions.

\subsection{Normal operation}

Fig. 5 displays RSCAD simulation waveforms superimposed on their PSCAD equivalents, where PS and RT subscripts stand for PSCAD and RTDS simulations respectively. In the simulations of the DC grid in Fig. 4, converter $T_{3}$ controls the DC grid voltage at $640 \mathrm{kV}$, whilst $T_{1}$ and $T_{2}$ are operated as follows: at $\mathrm{t}=2 \mathrm{~s}, \mathrm{~T}_{2}$ ramps its active power from 0 to $600 \mathrm{MW}$ at a rate of $1200 \mathrm{MW} / \mathrm{s}$; at $\mathrm{t}=2.5 \mathrm{~s}, \mathrm{~T}_{1}$ ramps its active power output from 0 to $600 \mathrm{MW}$ at the same rate whereas within $\mathrm{t}=4$ $5 \mathrm{~s}$ it reverses power from $600 \mathrm{MW}$ to $-1000 \mathrm{MW}$. Throughout this paper, converters $T_{1}, T_{2}$ and $T_{3}$ maintain their reactive power outputs at zero. 
This paper is a post-print of a paper submitted to and accepted for publication in The 15th IET International Conference-AC and DC Power Transmission (ACDC 2019) and is subject to Institution of Engineering and Technology Copyright. The copy of record is available at IET Digital Library.

The active power and DC voltage in Fig. 5 (a) and (b) show that the DC voltage controlling converter $\mathrm{T}_{3}$ (HB-MMC) regulates its DC link voltage tightly around $640 \mathrm{kV}$ and adjust its active power exchange with the $\mathrm{AC}$ grid $\mathrm{G}_{3}$ as the power controlling converters $\mathrm{T}_{1}$ (hybrid MMC) and $\mathrm{T}_{2}$ (FB-MMC) vary their active power set-points. These expected behaviours

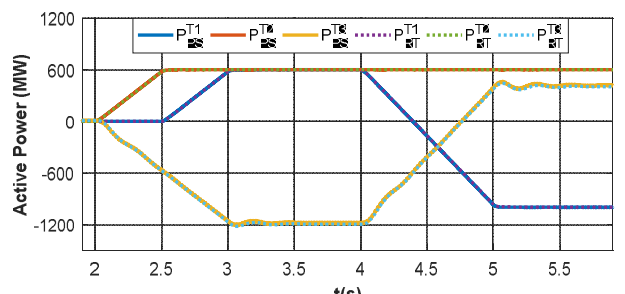

(a)

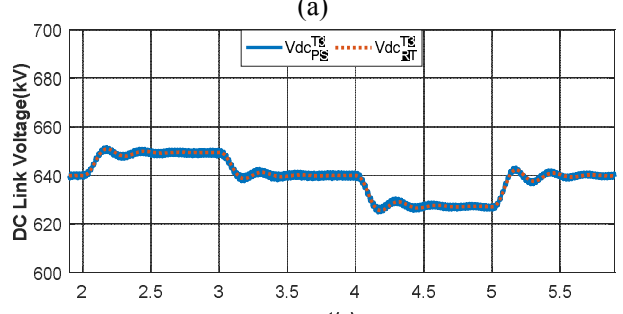

(b)

Fig. 5: Simulation waveforms that validate the steady-state performance and different dynamics of the offline DC grid model against that of the real-time equivalents as converters $T_{1}$ and $T_{2}$ vary their active power set-points (realtime superimposed on the offline): (a) active powers of the $T_{1}, T_{2}$ and $T_{3}$, (b) $\mathrm{DC}$ voltage of the converter terminal $\mathrm{T}_{3}$.

are replicated accurately by both the offline PSCAD and realtime RTDS simulation waveforms, see Fig. 5 (a) and (b).

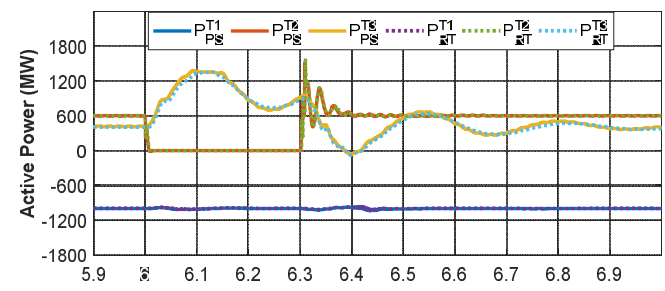

(a)

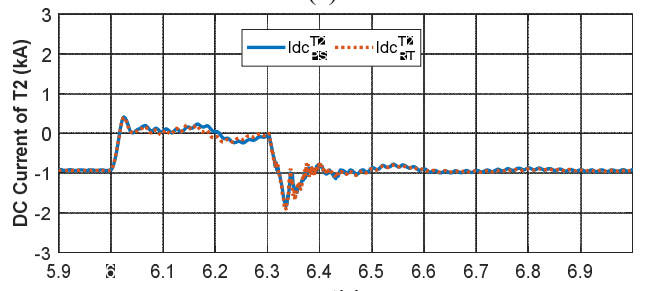

(c)

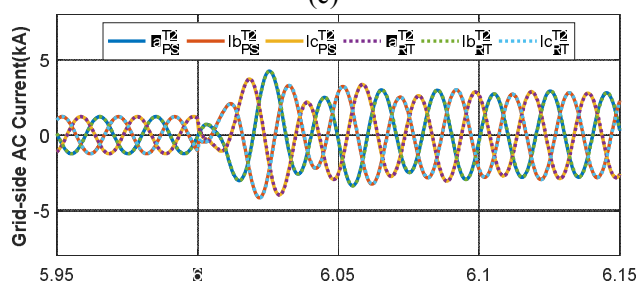

(e)

\subsection{Three-phase-to-ground AC fault}

Fig. 6 shows real-time RTDS simulation waveforms superimposed on their PSCAD equivalents when the system is subjected to a $300 \mathrm{~ms}$ temporary three-phase $\mathrm{AC}$ fault at converter $\mathrm{T}_{2} \mathrm{AC}$ terminal at $\mathrm{t}=6 \mathrm{~s}$. In the pre-fault condition, converters $T_{1}$ and $T_{2}$ control their active power outputs at $500 \mathrm{MW}$ and $600 \mathrm{MW}$ respectively, and converter $\mathrm{T}_{3}$ maintains the DC grid voltage at $640 \mathrm{kV}$.

Fig. 6 (a) shows the active powers of converters $T_{1}, T_{2}$ and $T_{3}$ measured at the grid sides of the transformers $B_{1}, B_{2}$ and $B_{3}$ respectively. The DC voltage shown in Fig. 6 (b) is briefly disturbed at the occurrence of the three-phase AC fault at $\mathrm{T}_{2}$, which creates a temporary imbalance between $\mathrm{AC}$ and $\mathrm{DC}$ powers. The brief drop observed in the DC voltage is an indication of the deficit in the DC power as a result of a loss of the active power from the converter $T_{2}$, see Fig. 6 (a) - (c). During the fault, $T_{2}$ operates at current limit as seen in the arm and output phase currents displayed in Fig. 6 (d) and (e). Notice that the DC components of the arm current of $\mathrm{T}_{2}$ drop to zero when its active power transfer capability collapses with the AC voltage at $B_{2}$ down to zero as shown in Fig. 6 (f). Since simulation waveforms displayed in Fig. 6 (a) through (f) show good agreement between the offline PSCAD and real-time RTDS models, and in line with broader theoretical understanding of DC grid behaviours during AC faults; it is concluded that both models are well-suited for AC fault studies of complex DC grids that employ different converter topologies.

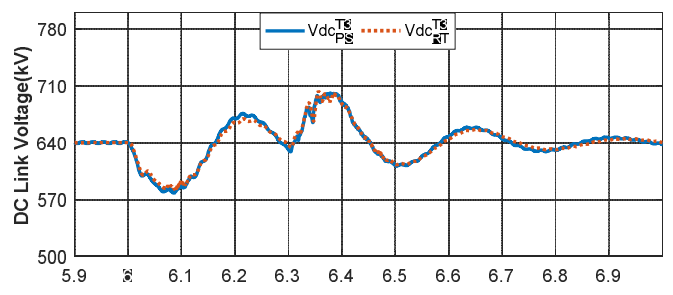

(b)

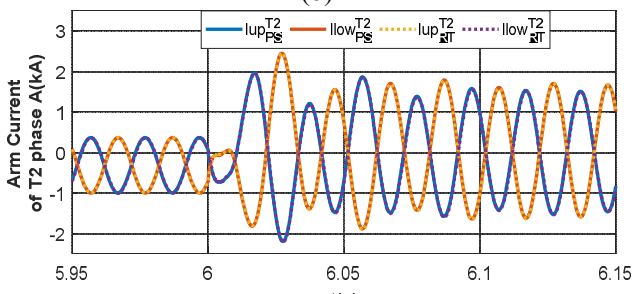

(d)

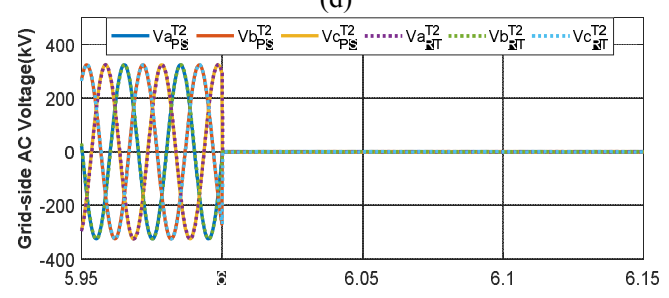

(f)

Fig. 6: Simulation waveforms of the offline DC grid model when converter $T_{2}$ is subjected to a solid three-phase symmetrical AC fault at $B_{2}$ : (a) Active powers of the converter terminals $\mathrm{T}_{1}, \mathrm{~T}_{2}$ and $\mathrm{T}_{3}$, (b) DC voltage of the converter terminal $\mathrm{T}_{3}$, (c) DC current of the $\mathrm{T}_{2}$ terminal, (d) Samples of the upper and lower arm currents of $\mathrm{T}_{2}$, (e) Converter $\mathrm{T}_{2}$ three-phase output currents measured at $\mathrm{B}_{2}$, (f) Converter $\mathrm{T}_{2}$ three-phase voltages measured at $\mathrm{B}_{2}$. 
This paper is a post-print of a paper submitted to and accepted for publication in The 15th IET International Conference-AC and DC Power Transmission (ACDC 2019) and is subject to Institution of Engineering and Technology Copyright. The copy of record is available at IET Digital Library.

\subsection{Pole-to-pole DC short circuit fault}

This section presents DC fault simulation waveforms when a permanent pole-to-pole DC short circuit is applied at the main DC fault node $\left(F_{2}\right)$ at $t=4 s$ and both converters $T_{1}$ and $T_{2}$ control their active powers at $600 \mathrm{MW}$ prior to the fault. All converters are blocked after $50 \mu \mathrm{s}$ after fault inception. Fig. 7 (a) and (b) show the pole-to-pole DC voltage at $\mathrm{F}_{2}$ and DC link currents of the three converters, with the DC link currents of the $\mathrm{T}_{1}$ (hybrid MMC) and $\mathrm{T}_{2}(\mathrm{FB}-\mathrm{MMC})$ drop to zero after the activation of the converters blocking, while converter $\mathrm{T}_{3}$ (HB$\mathrm{MMC}$ ) continues to feed current into the DC fault through its AC supply. The plots in Fig. 7 (c) show the active powers of converters $T_{1}$ and $T_{2}$ drop to zero immediately after blocking,

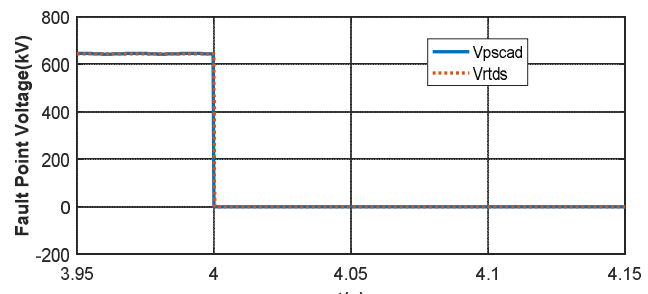

(a)

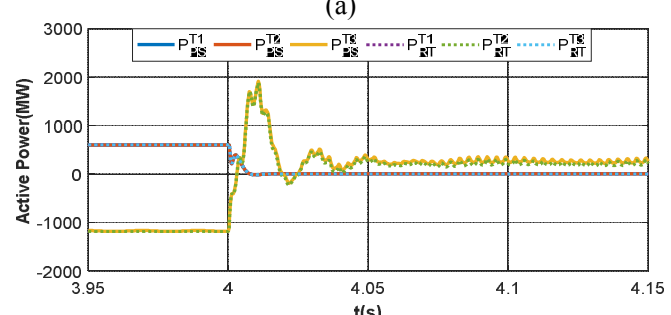

(c)

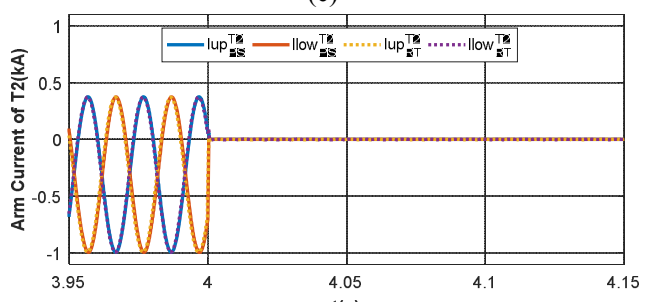

(e) while $\mathrm{T}_{3}$ continues to draw reduced active power from AC grid $\mathrm{G}_{3}$ to feed the entire system losses during the DC fault. Similar behaviour can be observed from the DC current as Fig. 7 (d), (e) and (f) show the arm currents of $T_{1}$ and $T_{2}$ drop to zero and that of the $T_{3}$ reverses direction and is fed from the AC side.

The DC voltages and currents, active powers and arm currents shown in Fig. 7 (a) through (f) are well matched between the offline and real-time simulation waveforms in terms of different dynamics and magnitudes during transients associated with the DC faults. Therefore, it is concluded that the presented models are well-suited for detailed DC fault studies in highly complex DC grids that consist of multiple voltage source converter topologies.

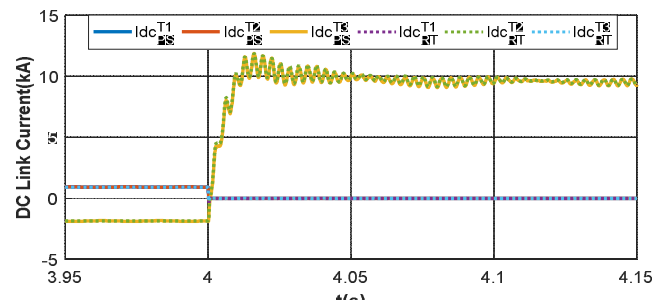

(b)

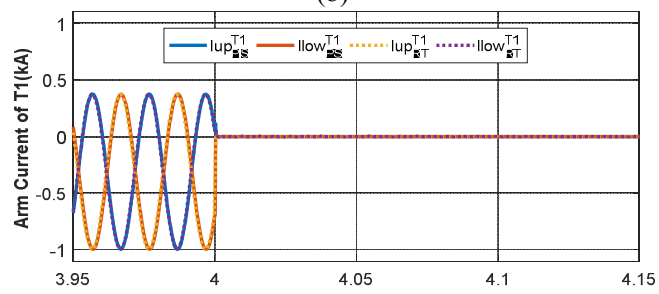

(d)

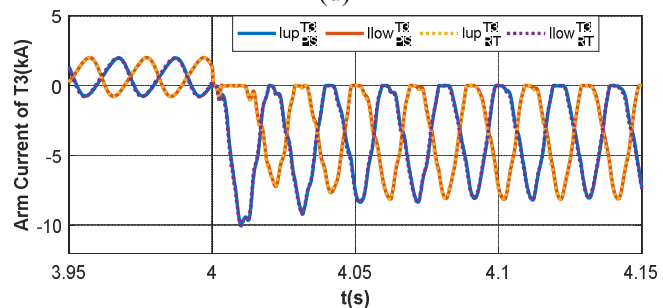

(f)

Fig. 7: Simulation waveforms of the offline DC grid model when a pole-to-pole DC short circuit fault is applied at the main DC node that links the three the converters: (a) Pole-to-pole DC fault measured at the fault point, (b) DC link current measured at DC terminals of converters $T_{1}, T_{2}$ and $T_{3}$, (c) Active powers of the converter terminals $T_{1}, T_{2}$ and $T_{3}$, and (d), (e) and (f) samples of the upper and lower arm currents of the converter terminals $T_{1}, T_{2}$ and $T_{3}$.

\section{Conclusion}

The rapid growth in the use of real-time hardware-in-the-loop simulation studies in order to facilitate extensive validations of the control and protection of HVDC systems in recent years have called for the development of rigorous models which are accurate and can be considered with high certainty as true representation of the physical systems. In response to this call, this paper has presented a summary of detailed quantitative study that assesses the interoperability of different converter topologies that operate side-by-side in a multi-terminal DC grid, with particular emphasis on the suitability of the models. Detailed examinations of the presented results, with the simulation waveforms of the real-time models superimposed on that of the offline PSCAD, reveal that both models being compared produce practically identical results during normal and abnormal conditions. On these bases, it has been concluded that the offline and real-time simulation models employed in this paper are well-suited for a wide range of DC grid studies such as normal operation, and AC and DC faults.

\section{Acknowledgements}

The project is sponsored by The National HVDC Centre.

\section{References}

[1] H. W. Dommel, "Digital Computer Solution of Electromagnetic Transients in Single-and Multiphase Networks," Power Apparatus and Systems, IEEE Transactions on, vol. PAS-88, no. 4, pp. 388-399, 1969.

[2] U. N. Gnanarathna, A. M. Gole, and R. P. Jayasinghe, "Efficient Modeling of Modular Multilevel HVDC 
This paper is a post-print of a paper submitted to and accepted for publication in The 15th IET International Conference-AC and DC Power Transmission (ACDC 2019) and is subject to Institution of Engineering and Technology Copyright. The copy of record is available at IET Digital Library.

Converters (MMC) on Electromagnetic Transient Simulation Programs," Power Delivery, IEEE Transactions on, vol. 26, no. 1, pp. 316-324, 2011.

[3] G. P. Adam and B. W. Williams, "Half- and Full-Bridge Modular Multilevel Converter Models for Simulations of Full-Scale HVDC Links and Multiterminal DC Grids," IEEE Journal of Emerging and Selected Topics in Power Electronics, vol. 2, no. 4, pp. 1089-1108, 2014.

[4] C. Oates and C. Davidson, "A comparison of two methods of estimating losses in the Modular Multi-Level Converter," in Power Electronics and Applications (EPE 2011), Proceedings of the 2011-14th European Conference on, 2011, pp. 1-10.

[5] G. P. Adam, P. Li, I. A. Gowaid, and B. W. Williams, "Generalized switching function model of modular multilevel converter," in 2015 IEEE International Conference on Industrial Technology (ICIT), 2015, pp. 2702-2707.

[6] R. Li, L. Xu, and D. Guo, "Accelerated switching function model of hybrid MMCs for HVDC system simulation," IET Power Electronics, vol. 10, no. 15, pp. 2199-2207, 2017.

[7] J. Xu, A. M. Gole, and C. Zhao, "The Use of AveragedValue Model of Modular Multilevel Converter in DC Grid," IEEE Transactions on Power Delivery, vol. PP, no. 99, pp. 1-1, 2014.

[8] F. B. Ajaei and R. Iravani, "Enhanced Equivalent Model of the Modular Multilevel Converter," Power Delivery, IEEE Transactions on, vol. PP, no. 99, pp. 1-1, 2014.

[9] J. Peralta, H. Saad, S. Dennetiere, J. Mahseredjian, and S. Nguefeu, "Detailed and averaged models for a 401-level MMC-HVDC system," in 2013 IEEE Power \& Energy Society General Meeting, 2013, pp. 1-1.

[10] J. Xu, A. M. Gole, and C. Zhao, "The Use of AveragedValue Model of Modular Multilevel Converter in DC Grid," IEEE Transactions on Power Delivery, vol. 30, no. 2, pp. 519-528, 2015.

[11] D. Guo et al., "Detailed quantitative comparison of halfbridge modular multilevel converter modelling methods," presented at the The 14th IET International Conference on AC and DC Power Transmission (ACDC 2018), China, 28-30 June 2018, 2018.

[12] H. Saad, K. Jacobs, W. Lin, and D. Jovcic, "Modelling of MMC including half-bridge and Full-bridge submodules for EMT study," in 2016 Power Systems Computation Conference (PSCC), 2016, pp. 1-7.

[13] S. Denneti et al., "Validation of a MMC model in a realtime simulation platform for industrial HIL tests," in 2015 IEEE Power \& Energy Society General Meeting, 2015, pp. 1-5.

[14] R. Li, L. Xu, L. Yao, and B. W. Williams, "Active Control of DC Fault Currents in DC Solid-State Transformers During Ride-Through Operation of MultiTerminal HVDC Systems," IEEE Transactions on Energy Conversion, vol. 31, no. 4, pp. 1336-1346, 2016.

[15] Z. Rong, L. Xu, L. Yao, and B. W. Williams, "Design and Operation of a Hybrid Modular Multilevel Converter," Power Electronics, IEEE Transactions on, vol. 30, no. 3, pp. 1137-1146, 2015.
[16] W. Xiang, W. Lin, L. Xu, and J. Wen, "Enhanced Independent Pole Control of Hybrid MMC-HVDC System," IEEE Transactions on Power Delivery, vol. PP, no. 99, pp. 1-1, 2017.

[17] G. P. Adam and I. E. Davidson, "Robust and Generic Control of Full-Bridge Modular Multilevel Converter High-Voltage DC Transmission Systems," IEEE Transactions on Power Delivery, vol. 30, no. 6, pp. 24682476, 2015.

[18] R. Li, G. P. Adam, D. Holliday, J. E. Fletcher, and B. W. Williams, "Hybrid Cascaded Modular Multilevel Converter With DC Fault Ride-Through Capability for the HVDC Transmission System," IEEE Transactions on Power Delivery, vol. 30, no. 4, pp. 1853-1862, 2015.

[19] E. C. Mathew, M. B. Ghat, and A. Shukla, "A Generalized Cross-Connected Submodule Structure for Hybrid Multilevel Converters," IEEE Transactions on Industry Applications, vol. 52, no. 4, pp. 3159-3170, 2016.

[20] Z. Suo, G. Li, L. Xu, R. Li, W. Wang, and Y. Chi, "Hybrid modular multilevel converter based multi-terminal DC/DC converter with minimised full-bridge submodules ratio considering DC fault isolation," IET Renewable Power Generation, vol. 10, no. 10, pp. 15871596, 2016.

[21] G. Bergna et al., "A Generalized Power Control Approach in ABC Frame for Modular Multilevel Converter HVDC Links Based on Mathematical Optimization," IEEE Transactions on Power Delivery, vol. 29, no. 1, pp. 386-394, 2014.

[22] Q. Tu, Z. Xu, and L. Xu, "Reduced Switching-Frequency Modulation and Circulating Current Suppression for Modular Multilevel Converters," Power Delivery, IEEE Transactions on, vol. 26, no. 3, pp. 2009-2017, 2011.

[23] N. Ahmed, L. Angquist, S. Norrga, A. Antonopoulos, L. Harnefors, and H. Nee, "A Computationally Efficient Continuous Model for the Modular Multilevel Converter," Emerging and Selected Topics in Power Electronics, IEEE Journal of, vol. PP, no. 99, pp. 1-1, 2014.

[24] H. Barnklau, A. Gensior, and S. Bernet, "Derivation of an equivalent submodule per arm for modular multilevel converters," in Power Electronics and Motion Control Conference (EPE/PEMC), 2012 15th International, 2012, pp. LS2a.2-1-LS2a.2-5. 